\title{
Balancing Risk of Thromboembolism and Bleeding in Patients with Cancer: Selecting Anticoagulant Therapy Based on Recent Clinical Trials
}

\author{
Authors: \\ *Katarzyna Rygiel \\ Medical University of Silesia, Katowice, Poland \\ *Correspondence to kasiaalpha@yahoo.co.uk \\ Disclosure: $\quad$ The author has declared no conflicts of interest. \\ Received: \\ 07.01.21 \\ Accepted: \\ 12.04.21 \\ Keywords: \\ Apixaban, cancer-associated thrombosis, direct oral anticoagulants (DOAC), \\ edoxaban, low-molecular-weight heparins (LMWH), non-vitamin $\mathrm{K}$ antagonist oral \\ anticoagulant (NOAC), rivaroxaban, venous thromboembolism (VTE).
}

Citation: EMJ Oncol. 2021; DOI/10.33590/emjoncol/21-00002.

\section{Abstract}

Patients with cancer may experience venous thromboembolism (VTE), leading to various medical complications or death, more often than the population without cancer. Moreover, patients with cancer usually experience both higher rates of recurrent VTE and bleeding. For the past decade, low-molecular-weight heparin (LMWH) has been considered a standard therapy for VTE related to cancer; however, daily injections of LMWH have augmented the burden of neoplastic disease and decreased adherence to therapy in some patients.

At present, direct oral anticoagulants (DOAC) such as factor Xa inhibitors (e.g., rivaroxaban, edoxaban, and apixaban) have been recommended as a new treatment modality, mostly because of their convenient use (i.e., the oral route of delivery) for the patient population with cancer. Notably, large recent randomised controlled trials that have compared DOACs with LMWH in patients with malignancies have revealed that DOACs represent a valuable alternative to LMWH for the therapy of VTE related to cancer. Despite their unique advantages, the DOACs may not be appropriate for some groups of patients with cancer due to their elevated risk of bleeding, among other factors.

This mini-review presents the main findings from some recent randomised controlled trials, comparing the use of DOACs and LMWH for the management of VTE associated with malignancy. It highlights the efficacy, safety, and various other considerations of treatment and prophylaxis of VTE depending on the individual patient context. It provides current guidance on the selection of the optimal anticoagulant for comprehensive and personalised patient care.

\section{INTRODUCTION}

group of patients, the rates of recurrent VTE and bleeding complications are higher than in

Venous thromboembolism (VTE) is one of the main reasons for morbidity and mortality among patients with malignancies. ${ }^{1}$ In addition, in this the general population. Over the past decade, low-molecular-weight heparin (LMWH) has been the standard of care for treatment of VTE related to cancer. ${ }^{1}$ However, its injectable form 
of administration has been inconvenient and thus patient compliance has been reduced and quality of life has been impaired. Furthermore, anticoagulation with vitamin $\mathrm{K}$ antagonists (VKA), such as warfarin, which requires frequent laboratory testing and is often complicated by bleeding or multiple drug-drug or drug-food interactions, was not a satisfactory solution for a majority of patients with cancer. Under these circumstances, direct oral anticoagulants (DOAC) have recently emerged as a desirable treatment option for patients with cancer-related VTE. ${ }^{2}$

DOACs include the direct thrombin inhibitor dabigatran and the direct factor $\mathrm{Xa}$ inhibitors, such as rivaroxaban, apixaban, and edoxaban. ${ }^{3}$ From a practical point of view, the oral route of delivery for DOACs, minor pharmacologic interactions, and no requirement for continuous laboratory parameter monitoring represent definite advantages. ${ }^{3}$ Regardless of particular anticoagulant selection, anticoagulation therapy has usually been more complicated among patients with cancer, who are characterised by higher rates of VTE and bleeding episodes than patients without malignancies. Since the comprehensive care for patients with cancer requires an individualised approach, physicians have to take into consideration different factors, such as prevention of recurrent VTE, bleeding episodes, interactions with anti-cancer therapies, administration, frequency of laboratory test monitoring, comorbidities, and patient preferences. ${ }^{3}$ In addition to initial anticoagulation for VTE in the patient with malignancy, primary prevention (e.g., before the first VTE event) and extended anticoagulation therapy (e.g., over the initial period of 6 months or 1 year) are valid considerations, especially among highrisk patients in whom risk stratification and prediction scores should be simultaneously assessed. ${ }^{4}$ It should be underscored that in spite of the unquestionable advantages of DOACs, these medications can be inappropriate for some groups of patients because of their elevated risk of major bleeding, potential exacerbation of some medical conditions, extremes of body mass (overweight or underweight), and other factors (e.g., relating to tumour type, location, stage, and therapy). ${ }^{2}$

This article outlines recent clinical guidelines on various aspects of cancer-related VTE. Furthermore, this mini-review presents the main findings from recent large randomised clinical trials (RCT) comparing the use of DOACs and LMWH for the management of VTE associated with malignancy. It highlights the efficacy, safety, and various other considerations of treatment and prophylaxis of cancer-related VTE, depending on the individual patient's clinical context. It discusses some important topics relevant to the selection of anticoagulants for personalised management of patients with malignancies and associated VTE.

\section{CHALLENGES OF ANTICOAGULATION IN PATIENTS WITH MALIGNANCY- ASSOCIATED THROMBOSIS}

VTE is a common medical complication in the population of patients with cancer, occurring in approximately $20 \%$ of these patients. ${ }^{4}$ Furthermore, different anti-cancer therapies (e.g., cytotoxic chemotherapy [CHT], radiation therapy, hormonal therapy [HT], targeted therapy, immune therapy, and surgery) can additionally augment VTE risk. ${ }^{4}$ Typically, patients with cancer-related VTE have more hospital admissions, higher rates of metastases, and worse overall survival (OS) rates than patients with cancer without VTE. ${ }^{5}$ Unfortunately, VTE is one of the main causes of mortality in patients with cancer, and thus, its prevention and treatment are of utmost importance. ${ }^{6}$

This problem is very challenging, since the prothrombophilic factors of malignant tumours can be extremely difficult to manage in many of these patients, despite the most intensive treatment efforts with modern anticoagulants. ${ }^{7}$ It should be highlighted that the complications of anticoagulation are quite serious in patients with cancer, who usually experience more episodes of recurrent VTE compared to patients without cancer, and have elevated rates of major bleeding compared to patients without cancer receiving anticoagulants. ${ }^{8}$ These adverse effects can be due to an anticoagulant's interactions with different anti-cancer agents, impaired oral intake, thrombocytopenia, or abnormal hepatic metabolism that influences the serum levels of anticoagulants. ${ }^{9}$ 


\section{LMWH FOR TREATMENT OF CANCER- ASSOCIATED VTE: PERSPECTIVES FROM THE CLOT AND CATCH TRIALS}

For over a decade, consensus guidelines have recommended LMWH as the standard of care for initial treatment of cancer-associated VTE, according to the data from leading RCTs, CLOT and CATCH, which compared LMWH to VKAs. 10,11 Subsequently, a meta-analysis of large RCTs has shown that $\mathrm{LMWH}$ decreased the recurrence of VTE compared to VKAs. ${ }^{12}$ However, LMWH might increase the risk of major bleeding, aggravating in this way the disease burden in patients with cancer-associated VTE. ${ }^{2}$ Notably, the CLOT and CATCH RCTs, comparing LMWH to VKA (warfarin) for cancer-related VTE, have revealed different results. ${ }^{10,11}$ The earlier CLOT trial had shown a significant decrease in VTE recurrence rate with dalteparin $(\mathrm{LMWH})$ versus warfarin treatment. ${ }^{10}$ In contrast, the later $\mathrm{CATCH}$ trial did not reveal the superiority of tinzaparin (LMWH) over warfarin."

However, a detailed assessment of the cancer burden and pre-existing risk of VTE may help elucidate the exact difference between these two RCTs. It should be noted that there were higher proportions of patients with metastatic cancer, ongoing anti-cancer therapies, and mortality rates in the CLOT trial compared to the CATCH trial. ${ }^{10,11}$ This suggests that the patient populations of these two RCTs were different. In particular in the CATCH trial, the patient population was less likely to develop recurrent VTE than the CLOT study patients, and this could have reduced the power of the trial to identify a significant difference in the adverse event rates (e.g., the reported rate of VTE episodes in the $\mathrm{CATCH}$ trial was lower than anticipated).10,11

\section{A PARADIGM SHIFT OF ANTICOAGULATION STRATEGIES FOR CANCER-ASSOCIATED VTE: THE EMERGENCE OF DOACS}

The emergence of DOACs has offered novel strategies for the therapy and prophylaxis of VTE among patients with cancer. ${ }^{3}$ In particular, the results of several Phase III trials have shown the non-inferiority of DOACs to warfarin for prevention of VTE recurrence, as well as lower rates of bleeding in the general population..$^{13}$ At present, DOACs have replaced warfarin as the standard of care for treatment of VTE in the majority of patients without cancer. ${ }^{13}$ Notably, the main RCTs on DOACs (as standard therapy for VTE in the population without cancer) have included only a small number of patients with cancer. $^{13}$ A meta-analysis of the patient population with cancer (from six of these Phase III clinical trials) has revealed significantly lower VTE recurrence rates in the DOAC arm than in the VKA arm, with a similar risk of major bleeding complications. ${ }^{13}$

Recent RCTs, including SELECT-D, Hokusai VTE Cancer, ADAM VTE, Caravaggio, CASSINI, and AVERT trials, comparing direct factor $\mathrm{Xa}$ inhibitors and LMWH for therapy or prevention of cancer-associated VTE, have focused on various aspects of the efficacy and safety of DOACs and LMWH in various clinical contexts (Table 1). ${ }^{14-21}$ Unlike the pivotal trials comparing DOACs to VKAs in the general population, the SELECT-D, Hokusai VTE Cancer, ADAM VTE, Caravaggio trials had strict inclusion criteria for patients with active cancer (Table 1). 14-17 The results of these four studies suggest that DOACs are noninferior to LMWH for preventing VTE recurrence in patients with cancer, and these reports have been convergent with a recent meta-analysis. ${ }^{22}$ However, based on the SELECT-D and Hokusai VTE Cancer trials, as well as the recent metaanalysis, the observed increased rates of bleeding events have included numerous gastrointestinal (GI) bleeds in the DOAC arms (e.g., such bleeding episodes occurred mostly in patients with oesophageal and gastric cancers). ${ }^{22,23}$ Notably, a safety analysis of the first half of the patient population enrolled into the SELECT-D trial has revealed a non-significant difference in major bleeding, especially upper Gl bleeding, between the rivaroxaban and dalteparin arms among patients with cancers of the oesophagus or gastroesophageal junction. However, it should be noted that the patients with these Gl tract cancers were subsequently excluded for the SELECT-D trial (Table 1). ${ }^{14}$ Similarly, a subgroup analysis of the Hokusai VTE Cancer trial has shown that in patients with $\mathrm{Gl}$ cancers there was a higher risk of major bleeding events originating from the Gl tract in the edoxaban arm than in the dalteparin arm (Table 1). ${ }^{15,23}$ 
Table 1: Comparison between direct oral anticoagulants and low-molecular-weight heparin (or placebo) for the management of cancer-associated thrombosis: the main findings from recent randomised clinical trials.

\begin{tabular}{|c|c|c|c|c|}
\hline Clinical trial & $\begin{array}{l}\text { Trial design and } \\
\text { sample size }\end{array}$ & Trial out-comes* & $\begin{array}{l}\text { Exclusion criteria } \\
\text { (cancer types and } \\
\text { other factors) }\end{array}$ & $\begin{array}{l}\text { Main results of } \mathrm{RCT}^{+} \text {and } \\
\text { implications for clinical } \\
\text { practice }\end{array}$ \\
\hline $\begin{array}{l}\text { SELECT-D; } \\
\text { Young et al., }{ }^{14} \\
2018\end{array}$ & $\begin{array}{l}\mathrm{RCT} \text {, open-label; } \\
\text { rivaroxaban versus } \\
\text { dalteparin in } \\
\text { treatment of patients } \\
\text { with malignancy- } \\
\text { associated VTE; } \\
\mathrm{N}=406\end{array}$ & $\begin{array}{l}\text { Recurrent VTE: } 4 \% \\
\text { versus 11\%; major } \\
\text { bleeding: } 6 \% \text { versus } \\
\text { 4\%; CRNMB: 13\% } \\
\text { versus 4\% }\end{array}$ & $\begin{array}{l}\text { Oesophageal or } \\
\text { gastroesophageal } \\
\text { cancer; Basal cell skin } \\
\text { cancer, squamous cell } \\
\text { skin cancer; prior VTE, } \\
\text { high bleeding risk }\end{array}$ & $\begin{array}{l}\text { Rivaroxaban revealed } \\
\text { significantly lower rate } \\
\text { of recurrent VTE; major } \\
\text { bleeding rates were not } \\
\text { significantly different; } \\
\text { CRNMB rates were } \\
\text { significantly greater in the } \\
\text { rivaroxaban arm }\end{array}$ \\
\hline $\begin{array}{l}\text { Hokusai VTE } \\
\text { Cancer; Raskob } \\
\text { et al.,15 } 2018\end{array}$ & $\begin{array}{l}\text { RCT, open-label; } \\
\text { edoxaban versus } \\
\text { dalteparin in } \\
\text { treatment of patients } \\
\text { with malignancy- } \\
\text { associated VTE; } \\
\mathrm{N}=1050\end{array}$ & $\begin{array}{l}\text { Composite of } \\
\text { recurrent VTE or } \\
\text { major bleeding; } \\
\text { recurrent VTE: } 6.5 \% \\
\text { versus } 8.8 \% \text {; major } \\
\text { bleeding: } 5.6 \% \text { versus } \\
3.2 \% \text {; CRNMB: } 12.3 \% \\
\text { versus } 8.2 \%\end{array}$ & $\begin{array}{l}\text { Basal cell skin cancer, } \\
\text { squamous cell skin } \\
\text { cancer }\end{array}$ & $\begin{array}{l}\text { Edoxaban was non-inferior } \\
\text { to LMWH in combined } \\
\text { outcome of VTE recurrence } \\
\text { or major bleeding; major } \\
\text { bleeding occurred more } \\
\text { often in the edoxaban arm; } \\
\text { CRNMB rates were not } \\
\text { significantly different }\end{array}$ \\
\hline $\begin{array}{l}\text { ADAM VTE; } \\
\text { McBane et al., }{ }^{16} \\
2020\end{array}$ & $\begin{array}{l}\text { RCT, open-label; } \\
\text { apixaban versus } \\
\text { dalteparin in } \\
\text { treatment of patients } \\
\text { with malignancy- } \\
\text { associated VTE }\end{array}$ & $\begin{array}{l}\text { Recurrent VTE: } 3.4 \% \\
\text { versus } 14.1 \% \text {; major } \\
\text { bleeding: } 0.0 \% \text { versus } \\
2.1 \% \text {; CRNMB: } 6.2 \% \\
\text { versus } 4.2 \% .\end{array}$ & & $\begin{array}{l}\text { Significant reduction } \\
\text { in recurrent VTE with } \\
\text { apixaban; no significant } \\
\text { difference in bleeding rates }\end{array}$ \\
\hline $\begin{array}{l}\text { Caravaggio; } \\
\text { Agnelli et al.,17} \\
2020\end{array}$ & $\begin{array}{l}\text { RCT, open-label; } \\
\text { apixaban versus } \\
\text { dalteparin in } \\
\text { treatment of patients } \\
\text { with malignancy- } \\
\text { associated VTE; } \\
\mathrm{N}=1170\end{array}$ & $\begin{array}{l}\text { Recurrent VTE: } 5.6 \% \\
\text { versus } 7.9 \% \text {; major } \\
\text { bleeding: } 3.8 \% \text { versus } \\
\text { 4.0\%; CRNMB: } 9.0 \% \\
\text { versus } 6.0 \%\end{array}$ & $\begin{array}{l}\text { Primary brain } \\
\text { tumour, intracerebral } \\
\text { metastasis, acute } \\
\text { leukaemia, Basal cell } \\
\text { skin cancer, squamous } \\
\text { cell skin cancer; high } \\
\text { bleeding risk }\end{array}$ & $\begin{array}{l}\text { Apixaban was non-inferior } \\
\text { to dalteparin for treatment } \\
\text { of cancer-associated VTE, } \\
\text { without increased risk of } \\
\text { major bleeding; patients } \\
\text { with Gl cancer were not } \\
\text { excluded; GI bleeding } \\
\text { occurred in } 1.9 \% \text { of patients } \\
\text { in apixaban versus } 1.7 \% \text { in } \\
\text { the dalteparin arm }\end{array}$ \\
\hline $\begin{array}{l}\text { CASSINI; } \\
\text { Khorana et } \\
\text { al., }^{18,20} 2017\end{array}$ & $\begin{array}{l}\mathrm{RCT} \text {, open-label; } \\
\text { rivaroxaban } \\
\text { versus placebo for } \\
\text { preventing VTE in } \\
\text { high-risk ambulatory } \\
\text { patients with various } \\
\text { cancers, starting } \\
\text { systemic } \mathrm{CHT}(\mathrm{KS} \geq 2)\end{array}$ & $\begin{array}{l}\text { VTE occurrence: } \\
2.60 \% \text { versus } 6.41 \% ; \\
\text { major bleeding: } 1.98 \% \\
\text { versus } 0.99 \% ; \text { CRNMB: } \\
2.72 \% \text { versus } 1.98 \%\end{array}$ & $\begin{array}{l}\text { Occult VTE diagnosed } \\
\text { via venous duplex } \\
\text { ultrasound }\end{array}$ & $\begin{array}{l}\text { Rivaroxaban significantly } \\
\text { reduced the rate of VTE; } \\
\text { no difference in the rates of } \\
\text { major bleeding }\end{array}$ \\
\hline $\begin{array}{l}\text { AVERT; Kimpton } \\
\text { et al.., } 2018 ; \\
\text { Carrier et al., } \\
2019\end{array}$ & $\begin{array}{l}\text { RCT, open-label; } \\
\text { apixaban versus } \\
\text { placebo for } \\
\text { preventing VTE in } \\
\text { high-risk ambulatory } \\
\text { patients with active } \\
\text { cancers using CHT }\end{array}$ & $\begin{array}{l}\text { VTE occurrence: } 4.2 \% \\
\text { versus } 10.2 \% \text {; Major } \\
\text { bleeding: } 3.5 \% \text { versus } \\
\text { 1.8\%; CRNMB: } 7.3 \% \\
\text { versus } 5.5 \%\end{array}$ & & $\begin{array}{l}\text { Apixaban significantly } \\
\text { reduced the rate of VTE; } \\
\text { Major bleeding was } \\
\text { greater in ITT analysis; No } \\
\text { difference in CRNMB rates }\end{array}$ \\
\hline
\end{tabular}

*Treating VTE: DOACs versus LMWH arm; preventing VTE: DOACs versus placebo arm.

+DOACs versus LMWH, or DOACs versus placebo arm.

CHT: chemotherapy; CRNMB: clinically relevant non-major bleeding; DOAC: direct oral anticoagulants; DVT: deep venous thrombosis; GI: gastrointestinal; ITT: intention-to-treat; KS: Khorana score; LMWH: low-molecular-weight heparin; PE: pulmonary embolism; RCT: randomised clinical trial; VTE: venous thromboembolism. 
The appropriateness of DOAC use (e.g., rivaroxaban or edoxaban) among patients with Gl cancers remains questionable. At this point, the findings from the ADAM VTE trial, indicating possible superiority of apixaban without increased bleeding complications, have revealed that the results of a given study, exploring a particular DOAC such as apixaban, should not be generalised for the entire class of DOACs (Table 1). ${ }^{16}$ Notably in the Caravaggio trial, which compared the efficacy and safety of apixaban and dalteparin in patients with cancer-related VTE, approximately $30 \%$ of participants were diagnosed with $\mathrm{Gl}$ cancers (Table 1). ${ }^{17}$ In addition, patients with a pulmonary embolism (PE) made up over half of the participants in the apixaban and dalteparin arms. ${ }^{17}$ Approximately $20 \%$ of the participants were patients with incidental deep vein thrombosis or PE detected during diagnostic work-up, usually conducted for reasons unrelated to the suspected VTE. ${ }^{17}$ In contrast to prior studies with other DOACs, in the Caravaggio study the occurrence of major bleeding (e.g., systemic or $\mathrm{Gl}$ ) was almost identical in the apixaban and dalteparin arms. ${ }^{17}$ However, the clinical advantage of apixaban therapy, conducted for $>6$ months, should be evaluated in the future trials. Overall, apixaban and rivaroxaban represent a very convenient and safe treatment option for cancer-related VTE, which can be used from the beginning of anticoagulation therapy, particularly in patients with deep vein thrombosis and incidental PE. ${ }^{17}$

\section{THE PREVENTIVE ROLE OF DOAC IN PATIENTS WITH CANCER AND ELEVATED RISK OF VTE}

Two main RCTs, which explored the preventive role of DOACs in patients with cancer and elevated risk of VTE, include CASSINI and AVERT (Table 1)..$^{18-21}$ It should be underscored that the Khorana risk score (KS) was $>2$ in the participants of both of these trials.

The CASSINI trial examined the safety and efficacy of rivaroxaban in the prevention of cancer-related VTE. 18,20 Contrary to the AVERT study, in which patients were not tested for VTE at the study screening period, participants in the CASSINI trial underwent venous duplex ultrasound screening for VTE in both legs prior to entering the trial, and then every two months during the entire trial period. ${ }^{18,20}$ Notably, patients in whom an occult VTE was diagnosed were excluded from the CASSINI study (Table 1). ${ }^{18,20}$

In the AVERT trial, patients with an active malignancy receiving $\mathrm{CHT}$ (with a $\mathrm{KS}$ of $\geq 2$ ) were randomised to apixaban or placebo for 6 months. In the intention-to-treat analysis, the apixaban group had a decreased incidence of VTE compared to the placebo group (4.2\% versus $10.2 \%$, respectively). ${ }^{19,21}$ However, the apixaban group had an increased incidence of major bleeding (3.5\% versus $1.8 \%$ ) and clinically relevant non-major bleeding (7.3\% versus $5.5 \%)$ compared to the placebo group. ${ }^{19,21}$ There was no difference in OS between these two groups in the AVERT trial (Table 1)..$^{19,21}$

Moreover, it should be underscored that the CASSINI study had a greater proportion of participants with pancreatic cancer than the AVERT trial (32\% versus $13 \%$, respectively). ${ }^{18-21}$ In addition, in the CASSINI trial, the intentionto-treat analysis found no significant reduction in VTE events after 6 months in the rivaroxaban arm compared to the placebo, and no increased risk of major bleeding. ${ }^{18,20}$ However, in the ontreatment analysis, rivaroxaban significantly reduced VTE compared to placebo (2.6\% versus $6.4 \%$, respectively). ${ }^{18,20}$ These findings suggest that in the AVERT and CASSINI studies the application of the KS (e.g., KS of $\geq 2$ ), resulted in more precise evaluation of low-dose DOAC versus LMWH therapy in comparison to the unselected population, assessed in the prior LMWH trials. ${ }^{24}$ In fact, the AVERT study had slightly more patients with $\mathrm{KS}$ scores of $\geq 4$ than the CASSINI trial (8.9\% versus $6.6 \%$, respectively). ${ }^{19,21}$

It should be highlighted that each of these trials excluded certain sub-populations of patients with cancer (e.g., who had Eastern Cooperative Oncology Group [ECOG] performance status of 3 or 4, cerebral metastases, and thrombocytopenia of $\left.<50 \times 10^{9} / \mathrm{L}\right)$. Notably, a recent retrospective study has shown no increase in bleeding rates among patients with primary brain tumours or brain metastases in those receiving DOACs compared with those receiving $\mathrm{LMWH} .{ }^{25}$ 


\section{AN INDIVIDUALISED SELECTION OF ANTICOAGULANTS IN CANCER- ASSOCIATED VTE: A LOOK FROM THE PATIENT'S PERSPECTIVE}

According to the International Society for Thrombosis and Haemostasis (ISTH), DOACs have been recommended for patients with cancerrelated VTE, a low risk of bleeding complications, and low probability of pharmacologic interactions with current medications. ${ }^{26}$ Similarly, the National Comprehensive Cancer Network (NCCN) has recommend the use of particular DOACs as follows: rivaroxaban as a monotherapy, apixaban for patients who have contraindications to LMWH (or decline therapy with LMWH), and edoxaban following initial heparin therapy. ${ }^{27}$ It should be highlighted that DOACs have some important advantages, such as convenient oral route of delivery, established dosing, no requirement for laboratory monitoring, and few interactions with anti-cancer therapies or other medications. ${ }^{28}$ As a consequence, DOACs are usually more acceptable to many patients (e.g., those who require a prolonged anticoagulation), which has a positive impact on their adherence to therapy and quality of life.$^{27,28}$

Nevertheless, DOACs are not the perfect solution for every patient with cancer-associated VTE (Table 2). 4,9,14,15,29-32 Unquestionably, the oral route of administration is a big positive of DOACs, while the subcutaneous injections of LMWH usually cause more inconvenience. However, somewhat unexpectedly, an analysis of patient interview records (including from the SELECT-D trial), has shown that many patients found injections acceptable as a component of comprehensive anti-cancer management. ${ }^{33}$ Moreover, it has been reported that the patient's preference for oral administration over injection was rather mild. On the other hand, the minor interference with anti-cancer treatment, low VTE recurrence rate, and low risk of major bleeding were the most appreciated features of $\mathrm{LMWH}$, according to several interviewed patients. ${ }^{34}$ This report was consisted with a previous international survey, including over 500 physicians and 800 patients, which showed that clinicians often over-estimate their patients' perceived burden of daily LMWH injections. ${ }^{35}$ Since numerous patients with cancer who are treated for VTE appreciate the effectiveness, safety, and comfort of such a treatment, physicians should discuss individual preferences with regard to anticoagulant choice with their patients. ${ }^{36}$

\section{BIOAVAILABILITY AND PHARMACOLOGIC INTERACTIONS OF DOAC}

While multiple pharmacologic interactions with VKAs have been known, there is a scarcity of information about interactions between DOACs and anti-cancer agents. It should be noted that rivaroxaban, edoxaban, and apixaban, factor Xa inhibitors, are metabolised via the cytochrome P450 3A4 (CYP3A4) and cytochrome P450 2J2 pathways; ${ }^{7}$ in contrast, another DOAC, dabigatran (a direct thrombin inhibitor), is metabolised by P-glycoprotein pathways. ${ }^{37}$ In general, DOACs have fewer drug interactions compared to VKAs. However, interactions have been encountered with some commonly used anti-cancer agents (e.g., $\mathrm{CHT}$, targeted therapy with tyrosine kinase inhibitors, and HT); e.g., certain anti-neoplastic medications (CHT: doxorubicin or vinblastine; $\mathrm{HT}$ : enzalutamide and dexamethasone) that induce P-glycoprotein or CYP3A4 can cause a decrease in DOAC blood levels. ${ }^{37}$ Some other anti-cancer agents (e.g., tyrosine kinase inhibitors: imatinib, dasatinib, lapatinib, nilotinib, or sunitinib; HT: tamoxifen) inhibiting P-glycoprotein or CYP3A4 can cause an increase in DOAC blood levels. ${ }^{37}$ Unfortunately, it still remains unclear which interactions are clinically relevant. For this reason, physicians need to be vigilant and regularly communicate with pharmacists to determine whether certain interactions with DOACs could be potentially harmful to individual patients. Moreover, Gl problems in patients with cancers can potentially alter drug delivery and absorption of DOACs. ${ }^{37}$

An ability to reverse anticoagulation is important, especially for older and more frail patients who may experience the most serious consequences of bleeding. Reversal agents for DOACs include idarucizumab (a Fab antibody fragment rapidly reversing the effects of dabigatran $)^{38}$ and andexanet alfa (a recombinant modified human $\mathrm{FXa}$ protein that binds factor $\mathrm{Xa}$ inhibitors and thus reduces anti-Xa activity). ${ }^{39}$ However, these agents are not readily available and very expensive. 
Table 2: Clinical considerations for selection of anticoagulation therapy in patients with cancer-associated thrombosis.

\begin{tabular}{|c|c|c|c|}
\hline $\begin{array}{l}\text { Decision for individualised } \\
\text { choice of anti-coagulation } \\
\text { therapy }\end{array}$ & DOAC $^{4,9,14,15}$ & LMWH $^{4,9,14,15,31}$ & VKA $^{4,9,29-32}$ \\
\hline Yes & $\begin{array}{l}\text { No evidence of GI } \\
\text { cancer; low risk of major } \\
\text { bleeding; ease of therapy } \\
\text { is for the patient a 'top' } \\
\text { priority; absence of strong } \\
\text { pharmacologic interactions }\end{array}$ & $\begin{array}{l}\text { GI adverse effects of } \\
\text { CHT; nausea/vomiting, } \\
\text { impaired oral intake; poor } \\
\text { Gl absorption (feeding } \\
\text { tubes, s/p gastric or bowel } \\
\text { resections); pharmacologic } \\
\text { interactions with DOACs or } \\
\text { VKAs; motivated patient } \\
\text { willing to use injections for } \\
\text { extended period of time; } \\
\text { known increased bleeding } \\
\text { risk; recurrent cancer- } \\
\text { associated VTE while on } \\
\text { anticoagulants }\end{array}$ & $\begin{array}{l}\text { Any situation in which close } \\
\text { anticoagulant monitoring } \\
\text { is necessary (e.g., history } \\
\text { of multiple prior systemic } \\
\text { bleeds), poor Gl absorption, } \\
\text { or impaired metabolism; } \\
\text { advanced renal failure; } \\
\text { extremes of body weight } \\
(<50 \mathrm{~kg} \text { or }>150 \mathrm{~kg} \text { ) }\end{array}$ \\
\hline No & $\begin{array}{l}\text { Presence of active GI cancer; } \\
\text { history of GI bleeding; } \\
\text { extremes of body weight } \\
(<50 \mathrm{~kg} \text { or }>150 \mathrm{~kg}) \text {; renal } \\
\text { failure }\end{array}$ & $\begin{array}{l}\text { Strong aversion to injectable } \\
\text { therapy; perceived 'needle } \\
\text { fatigue'; renal failure; } \\
\text { extremes of body weight } \\
(<50 \mathrm{~kg} \text { or }>150 \mathrm{~kg})\end{array}$ & $\begin{array}{l}\text { Difficult access to a } \\
\text { laboratory monitoring INR }\end{array}$ \\
\hline
\end{tabular}

Yes: Patient is considered as a potentially good candidate for specific anticoagulation therapy; No: Patient is considered as a potentially poor candidate for specific anticoagulation therapy.

CHT: chemotherapy; DOAC: direct oral anticoagulant; GI: gastrointestinal; INR: international normalised ratio; LMWH: low-molecular-weight heparin; s/p: status post; VKA: vitamin K antagonist; VTE: venous thromboembolism.

Furthermore, impaired renal function related to advanced age or toxic effects of $\mathrm{CHT}$ can limit the use of anticoagulants such as DOACs and LMWH. In particular, dabigatran is not recommended for patients with reduced creatinine clearance, and apixaban and rivaroxaban should be used with great caution. ${ }^{29} \mathrm{LMWH}$ is mostly excreted renally, and thus also should be used with extreme caution in patients with renal insufficiency. ${ }^{9}$ It should be underscored that among several patients with malignancy-associated VTE, the degree of renal insufficiency has been related to the risk of major bleeding, which can further aggravate the clinical outcomes. ${ }^{30}$ In such patients, a VKA (warfarin) may be the best option, since this is the only anticoagulant that can be precisely monitored (Table 2). 4,9,29-32

\section{CONSIDERATIONS IN TREATMENT OF CANCER-ASSOCIATED VTE AMONG PATIENTS WITH A HIGH BLEEDING RISK}

In order to provide comprehensive support for specific clinical scenarios and address some challenges in the management of anticoagulation among patients with cancer at high bleeding risk (e.g., Gl tract and haematological cancers), some clinical scenarios are described below. It should be highlighted that some issues specific to patients with cancer, which often contribute to bleeding, include the extent, location, and histologic features of the cancer, requirements for invasive diagnostic or treatment procedures, and the development of thrombocytopenia from $\mathrm{CHT}$ or from the underlying malignancy. ${ }^{37}$ Other comorbidities, such as kidney impairment and coagulopathy due to hepatic dysfunction, disseminated intravascular coagulopathy, or sepsis, can further predispose to bleeding. 
Because of potentially serious bleeding complications, all patients require an individualised assessment of their bleeding versus thrombosis risk prior to possible anticoagulation (e.g., any bleeding sources should be promptly identified and managed). ${ }^{37}$

Among patients with cancer who experience minor bleeding episodes, anticoagulation can be applied if close monitoring has been provided. However, in the case of contraindications to anticoagulation, or when the risk of bleeding outweighs the benefit of treatment, the anticoagulants should be discontinued. In such situations, the VTE progression needs to be evaluated and, if necessary, inferior vena caval filter may be inserted. ${ }^{40}$ Furthermore, in cases of serious cancer- or CHT-induced thrombocytopenia, platelet transfusions can be applied to allow anticoagulation (e.g., therapeutic anticoagulation with LMWH can be given if the platelet $(P L T)$ count can be maintained $>50 \times 10^{9}$ /L. For PLT counts $20-50 \times 10^{9} / \mathrm{L}$, a half-dose LMWH can be given, and for PLT count $<20 \times 10^{9}$ $/ L$, a therapeutic dose of the anticoagulant should be stopped. ${ }^{40}$

In patients with intracranial malignancies, the management of VTE has been particularly difficult because of the danger of intracranial haemorrhage $(\mathrm{ICH}) .{ }^{41}$ According to a recent systematic literature review concerning the survival of patients with haematologic malignancies and $\mathrm{ICH}$, a median OS for such patients was in a range of approximately 3-6 weeks, while a median OS for the sub-population of patients who experienced $\mathrm{ICH}$ within 10 days of haematologic carcinoma diagnosis was only five days. Notably, the worse outcomes were correlated with $\mathrm{ICH}$ cases that appeared early, displayed multi-focal or intra-parenchymal bleeding, and had thrombocytopenia (resistant to transfusion), leukocytosis, or low scores on Glasgow Coma Scale (upon admission). Overall, the prognosis of patients with haematologic malignancies and $\mathrm{ICH}$ is poor. ${ }^{41}$ Some new light on this topic has been shed by a study that compared the rates of $\mathrm{ICH}$ in patients with brain tumours who were treated with DOACs versus LMWH. ${ }^{25}$ Based on this study, DOACs were related to a lower incidence of $\mathrm{ICH}$ in patients with primary brain tumours. ${ }^{25}$ However, physicians need to be cautious of various risk factors for $\mathrm{ICH}$ to make the most reasonable therapeutic decisions, in agreement with the patient's preferences. ${ }^{25,41}$

Similarly, a retroperitoneal hematoma (RPH) is a dangerous complication, encountered in some patients with cancer (e.g., with Gl tract and haematological cancers, or undergoing abdominal surgery). A retrospective analysis of the risk factors (including anticoagulation therapy), clinical features, treatments, and outcomes of $\mathrm{RPH}$ has revealed that almost $60 \%$ of patients have improved with medical management, while the remaining patients required surgical interventions (e.g., laparoscopy or laparotomy) or interventional radiology procedures. ${ }^{42}$ These findings reinforce the necessity of close monitoring and early interventions among patients in whom RPH has been suspected.

It should be highlighted that in the management of patients with cancer at high risk for bleeding and recurrent VTE, in the individual decisions for anticoagulation precise patient selection is crucial. ${ }^{40}$ In particular, DOACs are not indicated if a patient has $\mathrm{Gl}$ tract cancer, a history of $\mathrm{Gl}$ bleeding, body mass $<50 \mathrm{~kg}$ or $>150 \mathrm{~kg}$, or renal failure. ${ }^{40}$ Under these circumstances, LMWH can be an alternative to DOACs, especially in patients with decreased oral intake or reduced GI absorption (e.g., due to vomiting, feeding tubes, status post-stomach or bowel resections). ${ }^{40}$

\section{NEW AND SUSTAINED RECOMMENDATIONS FROM THE ASCO CLINICAL PRACTICE GUIDELINE UPDATE}

According to the American Society of Clinical Oncology (ASCO) Clinical Practice Guideline Update, the standard recommendations about prophylaxis and therapy of VTE in patients with cancer have been provided. ${ }^{40}$ There are the following changes, compared to previous recommendations: physicians may offer thromboprophylaxis with DOACs (apixaban or rivaroxaban) or $\mathrm{LMWH}$ to selected high-risk outpatients with malignancies; rivaroxaban and edoxaban were added to VTE therapy options; patients with brain metastases have been addressed for possible VTE treatment; and longterm post-operative LMWH administration has been expanded. ${ }^{40}$ 
Recommendations that will be continued are as follows: most inpatients with cancer and an acute medical illness require thromboprophylaxis during hospitalisation; thromboprophylaxis is not routinely recommended for every outpatient with malignancy; patients scheduled for major cancer surgery should receive prophylaxis starting before surgery and continuing for at least 7-10 days; and assessment of VTE risk should be performed periodically among patients with malignancies, and oncology teams should provide patient education, focused on the signs and symptoms of VTE. 40

Further trials are necessary to precisely explain how to manage individual patients from the heterogeneous cancer-related-VTE population in a more personalised manner, focused on achieving the subtle equilibrium between anti-thrombotic actions and bleeding risk.

\section{CONCLUSION}

Although one-fifth of patients with cancer experience an episode of VTE during the natural course of their malignancy, the risk of VTE differs among those patients. It should be emphasised that for VTE prevention, DOACs can provide a suitable option, especially among patients with low bleeding potential and high VTE risk.

With regard to VTE treatment, two main approaches have been recommended, including DOACs and LMWH. However, the precise identification of individual patients as candidates to one of these therapies is of utmost importance. For this reason, both the clotting and the bleeding risk assessment need to be performed (e.g., with an application of risk stratification tools and prediction scores, such as KS). It should be highlighted that many factors related to cancer itself (e.g., its type and stage); its therapy (e.g., concurrent CHT); and the patient's clinical context (e.g., medical comorbidities), functional status, and preferences are crucial for making well-balanced decisions in this area.

Therefore, clinical oncology practitioners, in tandem with their well-informed patients, need to be able to reasonably select from the anticoagulant 'menu': DOACs, LMWH, or VKA, depending on the particular patient's scenario.

\section{References}

1. Lyman $\mathrm{GH}$ et al. Venous thromboembolism prophylaxis and treatment in patients with cancer: American Society of Clinical Oncology clinical practice guideline update. J Oncol Pract. 2015;11(3):e442-4.

2. Ay $\mathrm{C}$ et al. Treatment of cancer-associated venous thromboembolism in the age of direct oral anticoagulants. Ann Oncol. 2019;30(6):897-907.

3. Al-Samkari H, Connors JM. The role of direct oral anticoagulants in treatment of can-cer-associated thrombosis. Cancers (Basel). 2018;10(8):271.

4. Khorana AA, Francis CW. Risk prediction of cancer-associated thrombosis: appraising the first decade and developing the future. Thromb Res. 2018;164 (Suppl 1):S706.

5. Watson HG et al. Guideline on aspects of cancer-related venous thrombosis. Br J Haematol. 2015;170(5):640-8.

6. Khorana AA et al. Thromboembolism is a leading cause of death in cancer patients receiving outpatient chemotherapy. J Thromb Haemost. 2007;5(3):632-4.

7. Al-Samkari H, Connors JM. Dual anticoagulation with fondaparinux and dabigatran for treatment of cancer-associated hypercoagulability. Am J Hematol. 2018;93(6):E156-8.

8. Prandoni $\mathrm{P}$ et al. Recurrent venous thromboembolism and bleeding complications during anticoagulant treatment in patients with cancer and venous thrombosis. Blood. 2002;100(10):3484-8.

9. Patel HK, Khorana AA. Anticoagulation in cancer patients: a summary of pitfalls to avoid. Curr Oncol Rep. 2019;21(2):18.

10. 10. Lee AYY et al. Low-molecularweight heparin versus a coumarin for the prevention of recurrent venous thromboembolism in patients with cancer. N Engl J Med. 2003;349(2):146-53.

11. Lee AYY et al. Tinzaparin vs warfarin for treatment of acute venous thromboembo-lism in patients with active cancer: a randomized clinical trial. JAMA. 2015;314(7):677-86.

12. Sobieraj DM et al. Anticoagulation for the treatment of cancer-associated throm-bosis: a systematic review and network meta-analysis of randomized trials. Clin Appl Thromb Hemost. 2018;24(Suppl 9):182-7S.

13. van Es $\mathrm{N}$ et al. Direct oral anticoagulants compared with vitamin $\mathrm{K}$ antagonists for acute venous thromboembolism: evidence from phase 3 trials. Blood. 2014;124(12):1968-75.

14. Young AM et al. Comparison of an oral factor Xa inhibitor with low molecular weight heparin in patients with cancer with venous thromboembolism: results of a randomized trial (SELECT-D). J Clin Oncol 2018;36(20):2017-23.

15. Raskob GE et al. Edoxaban for the treatment of cancer-associated venous thrombo-embolism. N Engl J Med. 2018;378(7):615-24.

16. McBane RD et al. Apixaban and dalteparin in active malignancyassociated venous thromboembolism: the ADAM VTE trial. J Thromb Haemost. 2020;18(2):411-21.

17. Agnelli $G$ et al. Apixaban for the treatment of venous thromboembolism associated 
with cancer. N Engl J Med. 2020;382(17):1599-607.

18. Khorana AA et al. Rivaroxaban for preventing venous thromboembolism in high-risk ambulatory patients with cancer: rationale and design of the CASSINI trial. Rationale and design of the CASSINI trial. Thromb Haemost. 2017;117(11):2135-45.

19. Kimpton $\mathrm{M}$ et al. Apixaban for the prevention of venous thromboembolism in high-risk ambulatory cancer patients receiving chemotherapy: rational and design of the AVERT trial. Thromb Res. 2018;164(Suppl 1):S124-9.

20. Khorana AA et al. Rivaroxaban for thromboprophylaxis in high-risk ambulatory pa-tients with cancer. $\mathrm{N}$ Engl J Med. 2019;380(8):720-8.

21. Carrier M et al. Apixaban to prevent venous thromboembolism in patients with can-cer. N Engl J Med. 2019;380(8):711-9.

22. Li A et al. Direct oral anticoagulant (DOAC) versus low-molecular-weight heparin ( $L M W H$ ) for treatment of cancer associated thrombosis (CAT): a systematic review and metaanalysis. Thromb Res. 2019;173:158-63.

23. Kraaijpoel $\mathrm{N}$ et al. Clinical impact of bleeding in cancer-associated venous throm-boembolism: results from the Hokusai VTE Cancer Study. Thromb Haemost. 2018;118(8):1439-49.

24. Agnelli G. Direct oral anticoagulants for thromboprophylaxis in ambulatory pa-tients with cancer. N Engl J Med. 2019;380(8):781-3.

25. Carney BJ et al. Intracranial hemorrhage with direct oral anticoagulants in patients with brain tumors. J Thromb Haemost. 2019:17(1):72-6.

26. Khorana AA et al. Role of direct oral anticoagulants in the treatment of cancer-associated venous thromboembolism: guidance from the SSC of the ISTH. J Thromb Haemost. 2018;16(9):1891-4.

27. Soff GA. Use of direct oral anticoagulants for treating venous thromboembolism in patients with cancer. J Natl Compr Cancer Netw. 2018;16(5S):670-3.

28. Riess $\mathrm{H}$ et al. Direct ora anticoagulants for the treatment of venous thromboembo-lism in cancer patients: potential for drug-drug interactions. Crit Rev Oncol Hematol. 2018;132:169-79.

29. Weber J et al. The efficacy and safety of direct oral anticoagulants in patients with chronic renal insufficiency: a review of the literature. Eur J Haematol. 2019;102(4):312-8.

30. Kooiman $\mathrm{J}$ et al. Impact of chronic kidney disease on the risk of clinical outcomes in patients with cancerassociated venous thromboembolism during anticoagulant treat-ment. J Thromb Haemost. 2013;11(11):1968-76.

31. Schulman $\mathrm{S}$ et al. Recurrent venous thromboembolism in anticoagulated patients with cancer: management and short-term prognosis. J Thromb Haemost. 2015;13(6):1010-8.

32. Marshall AL et al. Recurrence of venous thromboembolism in patients with cancer treated with Warfarin. Clin Appl Thromb Hemost. 2015;21(7):632-8.

33. Hutchinson A et al. Oral anticoagulation is preferable to injected, but only if it is safe and effective: an interview study of patient and carer experience of ora and in-jected anticoagulant therapy for cancer-associated thrombosis in the select-d trial. Pal-liat Med. 2019;33(5):510-7.

34. Noble S et al. Assessing patients' anticoagulation preferences for the treatment of cancer-associated thrombosis using conjoint methodology. Haematologica. 2015;100(11):1486-92

35. Cimminiello C, Anderson FA Jr. Physician and patient perceptions of the route of administration of venous thromboembolism prophylaxis: results from an international survey. Thromb Res. 2012;129(2):139-45.

36. Farge $D$ et al. International clinical practice guidelines including guidance for direct oral anticoagulants in the treatment and prophylaxis of venous thromboembolism in patients with cancer. Lancet Oncol. 2016;17(10):e452-66

37. Lee AYY, Peterson EA. Treatment of cancer-associated thrombosis. Blood. 2013;122(14):2310-17.

38. Pollack CV Jr et al. Idarucizumab for dabigatran reversal. N Engl J Med. 2015;373(6):511-20.

39. Connolly SJ et al. Andexanet Alfa for acute major bleeding associated with factor Xa inhibitors. N Engl J Med. 2016;375(12):1131-41.

40. Key NS et al. Venous thromboembolism prophylaxis and treatment in patients with cancer: ASCO clinical practice guideline update. J Clin Oncol. 2020;38(5):496520.

41. Raghavan A et al. Outcomes and clinical characteristics of intracranial hemorrhage in patients with hematologic malignancies: a systematic literature review. World Neu-rosurg. 2020;144:e15-24.

42. Sahu KK et al. Clinical spectrum, risk factors, management and outcome of patients with retroperitoneal hematoma: a retrospective analysis of 3-year experience. Expert Rev Hematol, 2020;13(5):545-55. 